\title{
STUDY OF CLINICAL PATTERN AND EFFECT OF COMORBIDITIES ON INCISIONAL HERNIA
}

Sanjay M. Datey¹, Nilesh Thakare², Abhishek Gurjar ${ }^{3}$, Anshuman Bajpai ${ }^{4}$, Anique Gajdhar 5 , Mohit Goyal6, Sneha Ninama7 , Vipul Golcha ${ }^{8}$

${ }_{1}^{1}$ Professor, Department of Surgery, SAMC and PGI, Indore.

${ }^{2}$ Consultant Surgeon, Nagpur.

${ }^{3}$ Resident, Department of Surgery, SAMC and PGI, Indore.

${ }^{4}$ Resident, Department of Surgery, SAMC and PGI, Indore.

${ }^{5}$ Resident, Department of Surgery, SAMC and PGI, Indore.

${ }^{6}$ Resident, Department of Surgery, SAMC and PGI, Indore.

${ }^{7}$ Resident, Department of Surgery, SAMC and PGI, Indore.

${ }^{8}$ Resident, Department of Surgery, SAMC and PGI, Indore.

\section{ABSTRACT}

\section{BACKGROUND}

Incisional hernia is very common problem in post-laparotomy patient. It increases morbidity and also affects quality of life in longterm. Countless procedures have been advocated for their cure. Numerous suggestions have been offered to prevent them. In spite of all precautions during surgery and meticulous repairs to cure them, we still come across a number of cases with incisional hernias and failure to repair of incisional hernias leading to "recurrent incisional hernia."

\section{MATERIALS AND METHODS}

This case series of incisional hernia, which was comprising of 38 patients over a period of two years in which the demographic profile, clinical presentation, comorbid conditions and outcome of repair was studied and the collected data analysed statistically.

\section{RESULTS}

Study showed that morbid obesity is the most important contributing factor in the causation of a "recurrent incisional hernia." Incisional hernia is a common iatrogenic complication of abdominal surgery and is cause of unwanted morbidity. Study showed that incisional hernia is a common problem in females after gynaecological operations. Obesity was found to be the most important factor when the effect of comorbidities was studied. Fifteen out of the thirty eight $(39.47 \%)$ patients came under the category of morbidly obese.

\section{CONCLUSION}

In this study, there was a group of 11 patients with history of unsuccessful repair of their incisional hernias for more than once leading to "recurrent incisional hernias." Out of these 11 patients, 6 were with a Body Mass Index (BMI) of more than 40 (morbid obesity, grade III).

\section{KEYWORDS}

Hernia, Incisional, Recurrent Hernia, Obesity.

HOW TO CITE THIS ARTICLE: Datey SM, Thakare N, Gurjar A, et al. Study of clinical pattern and effect of comorbidities on incisional hernia. J. Evolution Med. Dent. Sci. 2017;6(56):4197-4200, DOI: 10.14260/Jemds/2017/909

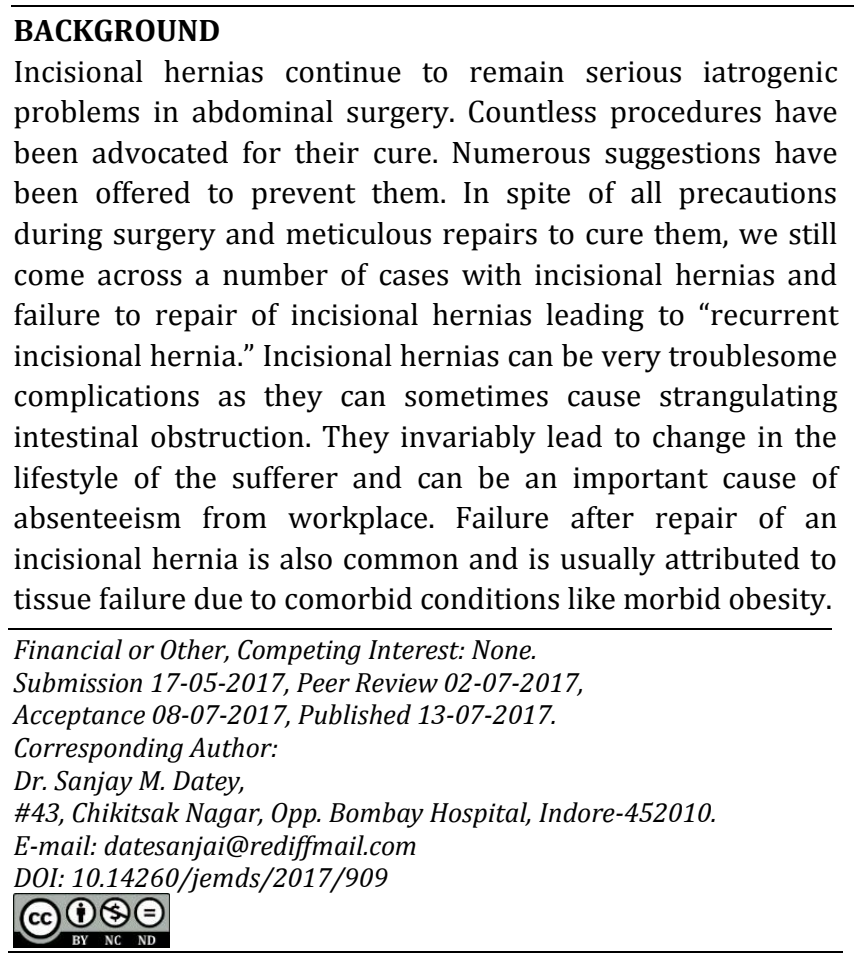
MATERIAL AND METHODS

This case series of the patients of incisional hernias was carried out over a period of two years. A total number of 38 cases were studied. All patients with incisional hernia who came to the hospital were included in this study. Patients with recurrent inguinal hernia were not included as we consider them to be of primarily hernias of different etiopathology.

As per the proforma of the study, a thorough workup of all patients was done. Detailed history pertaining to the surgery, which later on led to the incisional hernia was recorded, more stress was laid on the predisposing factors and comorbidities at the time of operation.

Thorough workup of all patients included a complete physical examination, weight in kilograms, height in meters, size of defect and blood chemistry, x-ray chest, ECG, renal and hepatic profiles were carried out.

Patients were evaluated for comorbidities like asthma, COPD, DM, morbid obesity, HTN, malignancies, nutritional status, weight and height at the time of first operation. BMI at the time of first operation, which led to incisional hernia was also recorded. 


\section{RESULTS}

All findings recorded were entered on a master chart and analysed. Following observation were noted.

\begin{tabular}{|c|c|c|}
\hline Patients & Numbers & Percentage \\
\hline Female & 29 & $76.31 \%$ \\
\hline Male & 9 & $23.68 \%$ \\
\hline \multicolumn{2}{|c|}{ Table 1. Male/Female Ratio in the Study } \\
\hline
\end{tabular}

Seventy six percent patients were female and the most common reason for their incisional hernia was a gynaecological operation either a hysterectomy or a LSCS.

\begin{tabular}{|c|c|c|}
\hline Age Group & Number of Patients & Percentage \\
\hline $25-30$ & 1 & $2.63 \%$ \\
\hline $31-35$ & 1 & $2.63 \%$ \\
\hline $36-40$ & 2 & $5.26 \%$ \\
\hline $41-45$ & 7 & $18.42 \%$ \\
\hline $46-50$ & 3 & $7.89 \%$ \\
\hline $51-55$ & 5 & $13.15 \%$ \\
\hline $56-60$ & 5 & $13.15 \%$ \\
\hline $61-65$ & 3 & $7.89 \%$ \\
\hline $66-70$ & 2 & $5.26 \%$ \\
\hline $71-75$ & 8 & $21.05 \%$ \\
\hline $76-80$ & 0 & 0 \\
\hline $81-85$ & 1 & $2.63 \%$ \\
\hline \multicolumn{2}{|c|}{ Table 2. Age Groups of the Patients } \\
\hline
\end{tabular}

The above table shows that the ages of the patients in this study varied from 29 to 82 years. The mean age is 56.02 years.

\begin{tabular}{|c|c|}
\hline Incision & Number of Cases \\
\hline McBurney & 2 \\
\hline Infraumbilical transverse & 2 \\
\hline Subcostal incision (Kocher's) & 2 \\
\hline Infraumbilical midline & 16 \\
\hline Supraumbilical midline & 13 \\
\hline Supraumbilical transverse & 1 \\
\hline Lumbar & 1 \\
\hline Paramedian & 1 \\
\hline
\end{tabular}

Out of the 38 patients studied, the commonest incisions responsible for the hernia were infraumbilical midline (16) and supraumbilical midline (13). Infraumbilical midline, alone was responsible for $42.10 \%$ of the incisional hernias studied.

\begin{tabular}{|c|c|}
\hline Name of Operation & Number of Patients \\
\hline LSCS & 18 \\
\hline Cholecystectomy & 3 \\
\hline Hysterectomy & 2 \\
\hline Appendicectomy & 2 \\
\hline Emergency laparotomy & 6 \\
\hline Laparotomy for malignancy & 2 \\
\hline Umbilical hernia & 4 \\
\hline Nephrolithotomy & 1 \\
\hline Table 4. Operations which Caused the Hernia \\
\hline
\end{tabular}

This table shows that LSCS (18) was the commonest operation responsible for the incisional hernias in this study (47.36\%).

\begin{tabular}{|c|c|}
\hline Time to Develop Hernia & Number of Patients \\
\hline 0 to 6 months & 9 \\
\hline 6 months to 1 year & 8 \\
\hline 1 year to 2 years & 9 \\
\hline 2 years to 3 years & 1 \\
\hline 3 years to 4 years & 3 \\
\hline 4 years to 5 years & 3 \\
\hline 5 years onwards & 5 \\
\hline \multicolumn{2}{|c|}{ Table 5. Duration after the Operation, } \\
which Resulted in Hernia \\
\hline
\end{tabular}

The above table shows the time period between the appearance of hernia and the operation responsible for it. 26 out of 38 patients reported about their hernia within 2 years of operation $(68.42 \%)$. Most of the incisional hernias are caused by either due to faulty surgical technique or a delayed tissue failure. Recurrence, which was noted within two years can be attributed to faulty surgical technique, whereas the incisional hernias, which were detected later than 2 years were the result of tissue failure.

\begin{tabular}{|c|c|c|}
\hline Mode of Presentation & No. of Patients & $\mathbf{\%}$ \\
\hline Swelling & 15 & $39.47 \%$ \\
\hline Pain & 9 & $23.68 \%$ \\
\hline Swelling and pain & 11 & $28.94 \%$ \\
\hline Pain, swelling and constipation & 3 & $7.89 \%$ \\
\hline
\end{tabular}

Table 6. Complaints by the Patient on Presentation

This chart shows swelling and pain were the dominant modes of presentation. Only two out of 38 (5.26\%) came with features suggestive of intestinal obstruction.

\begin{tabular}{|c|c|}
\hline Time Period & Number of Patients \\
\hline 2 Months & 1 \\
\hline 4 Months & 1 \\
\hline 5 Months & 1 \\
\hline 6 Months & 2 \\
\hline 7 Months & 1 \\
\hline 8 Months & 1 \\
\hline 9 Months & 1 \\
\hline 2 Years & 2 \\
\hline 5 Years & 1 \\
\hline Table 7. Time Period of Recurrence After Repair \\
\hline
\end{tabular}

This table shows the number of "recurrent" (recurrence after repair of hernia) and the time period after the surgery. Eight out of eleven $(72 \%)$ recurred within one year.

\begin{tabular}{|c|c|}
\hline Size of Defect & Number of Patients \\
\hline 2.25 Sq. cm. & 1 \\
\hline 2 Sq. cm. & 3 \\
\hline 4 Sq. cm. & 4 \\
\hline 6 Sq. cm. & 5 \\
\hline 8 Sq. cm. & 6 \\
\hline 12 Sq. cm. & 7 \\
\hline 15 Sq. cm. & 2 \\
\hline 120 Sq. cm. & 1 \\
\hline 24 Sq. cm. & 1 \\
\hline Table 8. Dimensions of the Defect in Square Centimetres
\end{tabular}

This table shows the dimensions of the defects in various patients. 


\begin{tabular}{|c|c|}
\hline Occupation & Number of Patients \\
\hline Housewife & 22 \\
\hline Teacher & 2 \\
\hline Driver & 2 \\
\hline Painter & 1 \\
\hline Baker & 1 \\
\hline Fisherman & 2 \\
\hline Shopkeeper & 1 \\
\hline Maid & 1 \\
\hline Labourer & 2 \\
\hline Baby-sitter & 1 \\
\hline Salesgirl & 1 \\
\hline Handicap (no work) & 1 \\
\hline Cleaner & 1 \\
\hline \multicolumn{2}{|c|}{ Table 9. Occupations of the Patients of Hernia } \\
\hline
\end{tabular}

This table shows the occupation of all patients studied in the group. Most of the patients were housewives (22).

\begin{tabular}{|c|c|c|c|}
\hline $\begin{array}{c}\text { Sl. } \\
\text { No. }\end{array}$ & Comorbidities & $\begin{array}{c}\text { No. of } \\
\text { Patients }\end{array}$ & Percentage \\
\hline 1. & Diabetes mellitus & 7 & $18.42 \%$ \\
\hline 2. & Hypertension & 16 & $42.10 \%$ \\
\hline 3. & Ischaemic heart disease & 4 & $10.52 \%$ \\
\hline 4. & Hyperthyroidism & 1 & $2.63 \%$ \\
\hline 5. & Bronchial asthma & 4 & $10.52 \%$ \\
\hline 6. & Neurological disorder & 2 & $5.36 \%$ \\
\hline 7. & Morbid obesity & 15 & $39.47 \%$ \\
\hline 8. & Malignant disease & 1 & $2.63 \%$ \\
\hline \multicolumn{4}{|c|}{ Table 10. Comorbidities } \\
\hline
\end{tabular}

This table shows the number of patients with different comorbidities, morbid obesity (with BMI above $30 \mathrm{~kg} / \mathrm{m}^{2}$ ) was found to be the commonest comorbidity (39.47\%) amongst the patients studied.

\begin{tabular}{|c|c|c|}
\hline BMI & Classification & Number of Patients \\
\hline$<18.5$ & Underweight & 3 \\
\hline $18.5-24.9$ & Normal weight & 7 \\
\hline $25.0-29.9$ & Overweight & 13 \\
\hline $30.0-34.9$ & Class I obesity & 8 \\
\hline $35.0-39.9$ & Class II obesity & 4 \\
\hline$>40$ & Class III obesity & 3 \\
\hline \multicolumn{2}{|c|}{ Table 11. BMI of all the 38 Patients } \\
\hline
\end{tabular}

This table shows the distribution of all the patients in the study with reference to their BMI. Twenty-eight patients out of the thirty eight were obese. This shows that obesity is the most significant factor in the causation of an incisional hernia.



Figure 1. 59-Year-Old Male, Operated for Perforation Peritonitis with Midline Incision

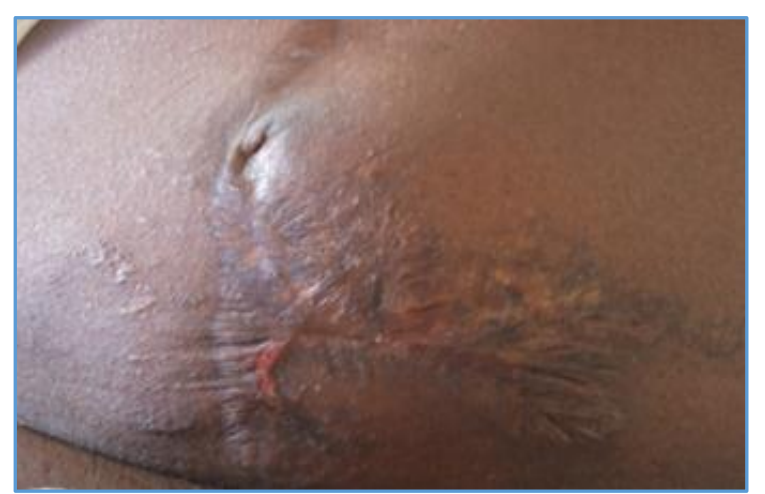

Figure 2. 57-Year-Old Male, Operated for RTA with Midline Incision showing Pressure Sore, BMI in Normal Range

\section{DISCUSSION}

Thirty eight cases of incisional hernias over a period of two years are presented in this study, which may not reflect all the aspects of the clinical pattern and effect of comorbidities as the series is small and follow up has been for a short period in most of the cases. Interestingly, obesity turned out to be the most common factor amongst the observed comorbidities.

Incisional hernia is a problem of great magnitude for an individual. Incisional hernia is an unexpected and hindering complication, which can influence daily life in such a manner that he or she could be considered invalid. Repeated admissions and operations have a physical, mental and financial impact on the patient. When a subsequent hernia repair dose not solve the problem, but results in a recurrence, the patient's quality of life maybe seriously affected.

One of the major aims of the study was correlation of comorbidities in patients of incisional hernia and recurrence of hernias after repair. Comorbidities commonly encountered in the patients were diabetes mellitus, hypertension and obesity. One of the patient had hyperthyroidism and one patient had malignancy of colon. Diabetes mellitus makes the patient more vulnerable to skin infections and thus postoperative wound infection and dehiscence. Diabetes 
mellitus should be corrected. All skin infections should be adequately treated at least one month before operation. ${ }^{1}$

Hypertension per se does not affect the wound healing and thus is not a significant comorbidity in relation to repair of incisional hernia. Severe uncontrolled hypertension can affect the outcome of anaesthesia and operation and preoperative control is mandatory.

Morbid obesity turned out to be the most common factor in the patients studied in these series. The weight of the panniculus adiposus itself pulls apart the surgical incision, and infection hampers wound healing. Hypertension, cardiac and renal disorders, diabetes and purulent intertrigo commonly accompany obesity and increase the morbidity of repair. Obese patients with large incisional hernias are especially at risk for postoperative septic complications, respiratory dysfunction and pulmonary emboli. Preoperative and postoperative prophylaxis for these problems is essential.

Normally, the intra-abdominal pressure ranges between 2 to $20 \mathrm{mmHg}$ ( $2 \mathrm{mmHg}$ in lying position, which increases to 20 mmHg on standing), which is extended from inside towards the abdominal wall. Abdominal wall muscles constantly work against this pressure to prevent herniation through weak spots of deep inguinal ring and umbilical scar. When the scar has a defect, the abdominal contents may start protruding through it due to the intra-abdominal pressure. Intraabdominal pressure increases during act of coughing, vomiting, defecation, parturition and urination. Certain conditions like chronic cough, chronic constipation, urinary obstruction, obesity, repeated pregnancies and postoperative abdominal distension may further increase the pressure unwantedly and increase the chance of incisional hernia. $2,3,4,5$ In obese individuals in excessive fat in omentum and subcutaneous tissue results in increased intra-abdominal pressure with excessive strain on the abdominal wound in the early postoperative period. Associated poor muscle tone and lack of muscle mass cause development of incisional hernia.

In the early phase of wound healing after a laparotomy, the separated edges of fascia are supported by sutures. Once the reorganisation of clot with formation of fibril network is done, the wound is strengthened. This early phase is critical, in the sense, if the conditions are unfavourable and haematoma formation or infection takes place, which separate the edges. This will not allow the union of edges and a gap will be formed. Diabetics, obese or nutritionally deficient patients are more prone to this phenomenon, either because of a seroma or because of early infection or because of poor collagen with weak fibril network.

Early incisional hernia is a defect, which is detected by patient in a short period of one to six months after the operation. It is invariably due to faulty closure technique. Late hernia is described as due to tissue failure or deterioration in the tensile strength of fibrous tissue with advancing age and obesity as the hernia is detected after several years of operation. Studies by the help of CT scan are coming with interesting findings in the very early period. It has been shown by serial scanning in the postoperative period that the distance between the two recti is more in the patients who later developed an incisional hernia. It can also have some predictive value about the occurrence of incisional hernia in a particular patient. ${ }^{6}$
Body Mass Index (BMI) of more than 30 is considered as morbid obesity. In our study, 15 out of 38 patients were morbidly obese with BMI of more than 30 (39.47\%). In this study, 11 patients with recurrent incisional hernia formed a major group (31\%). Out of these 11 patients, 6 were morbidly obese with a BMI of more than 40 (morbid obesity gr. III in $54 \%)$.

In this study, there was a group of 11 patients with history of unsuccessful repairs of their incisional hernias for more than once leading to a "recurrent incisional hernia." Out of these 11 patients, 6 were with a BMI of more than 40 (morbid obesity, grade III).

Recurrence after a surgical repair with mesh indicates towards a tissue failure leading to hernia formation. Increased intra-abdominal pressure, lack of activity and separation of muscle fibres due to adipose tissue are certain factors, which lead to weakening of the scar. ${ }^{7}$ Morbidly obese individuals are prone to get an incisional hernia and a recurrent hernia after a repair. Ideally, incisional hernia should never be operated upon in morbid obesity as the chances of failure are significantly higher. But, certain situations like strangulation in an incisional hernia, acute abdominal catastrophe make the surgery unavoidable. Prophylactic use of mesh in the abdominal repair of all morbidly obese can be a solution to this problem. This option can be considered with caution as recurrences are reported after the use of prophylactic mesh in bariatric surgeries. ${ }^{8}$

\section{CONCLUSION}

In this study, there was a group of 11 patients with history of unsuccessful repair of their incisional hernias for more than once leading to "recurrent incisional hernias." Out of these 11 patients, 6 were with a Body Mass Index (BMI) of more than 40 (morbid obesity, grade III).

\section{REFERENCES}

[1] Schnider SL, Kohn RR. Glucosylation of human collagen in aging and diabetes mellitus. J Clin Invest 1980;66(5):1179-81.

[2] Klinge U, Prescher A, Klosterhalfen B, et al. Development and pathophysiology of abdominal wall defects. Chirurg 1997;68(4):293-303.

[3] Bucknall TE, Cox PJ, Ellis H. Burst abdomen and incisional hernia: a prospective study of 1129 major laparotomies. $\mathrm{Br}$ Med J (Clin Res Ed) 1982;284(6320):931-3.

[4] Wissing J, van Vroonhoven TJ, Schattenkerk ME, et al. Fascia closure after midline laparotomy: results of a randomized trial. Br J Surg 1987;74(8):738-41.

[5] Regnard JF, Hay JM, Rea S, et al. Ventral incisional hernias: incidence, data of recurrence, localization and risk factors. Ital J Surg Sci 1988;18(3):259-65.

[6] Burger JW, Lange JF, Halm JA, et al. Incisional hernia: early complication of abdominal surgery. World Journal of Surgery 2005;29(12):1608-13.

[7] Haslam DW, James WP. Obesity. Lancet 2005;366(9492):1197-209.

[8] Herbert GS, Tausch TJ, Carter PL. Prophylactic mesh to prevent incisional hernia: a note of caution. Am J Surg 2009;197(5):595-8. 